\title{
A Bulky Mass of the Infra-Temporal Fossa
}

\section{Lezrag $\mathrm{M}^{* 1}$, Aboulfadl $\mathrm{M}^{2}$, Widadi $\mathrm{O}^{1}$, Abada $\mathrm{R}^{1}$, Rouadi $\mathrm{S}^{1}$, Roubal $\mathrm{M}^{1}$ and Mahtar $\mathrm{M}^{1}$ \\ ${ }^{1}$ Departement of ENT, 20August Hospital, Ibn Rochd University Hospital, Casablanca, Morocco \\ ${ }^{2}$ Faculty of Medicine and Pharmacy, Casablanca, Morocco}

*Corresponding author: Lezrag M, Department of ENT, 20 August Hospital, Ibn Rochd University Hospital, Casablanca, Morocco, E-mail: lezragmokamed13@gmail.com

Citation: Lezrag M, Aboulfadl M, Widadi O, Abada R, Rouadi S, et al. (2016) A Bulky Mass of the InfraTemporal Fossa. J Case Rep Stud 4(6): 605. doi: 10.15744/2348-9820.4.605

Received Date: August 28, 2016 Accepted Date: December 27, 2016 Published Date: December 29, 2016

\begin{abstract}
Tumors located in the parapharyngeal space are rare. They account for $0.5 \%$ of the whole tumors of the head and neck. Benign neoplasms are the most common with a rate of 70 to $80 \%, 40$ to $50 \%$ originate in the salivary glands; half of them are represented by the pleomorphic adenoma. We report the case of 38 old-year woman with in which the diagnosis of parapharyngeal space was made. The patient underwent a complete removal of the mass. The histological exam revealed a pleomorphic adenoma. No postoperative complications.
\end{abstract}

Keywords: Parapharyngeal Tumors; Oropharynx Mass; Pleomorphic Adenoma

\section{Introduction}

Tumors of para-pharyngeal space are rare, they represent $0.5 \%$ of all tumors of the head and neck [1,2]. $70 \%$ to $80 \%$ are benign tumors with $40 \%$ to $50 \%$ having their origins from salivary glands. The pleomorphic adenoma is the most common histological type $[1,3]$.

It can grow at the expense of accessory salivary glands or the deep lobe of the parotid. The clinical symptoms are poor, correlated to the mass effect exerted by the tumor on adjacent structures [4,5]. We report the case of a primitive pleomorphic adenoma in the para pharyngeal space and we expose, through a review of the literature, the clinical features, the diagnostic methods and the management of this pathology.

\section{Observation}

This is a 38 years old woman, who consulted for an oropharyngeal mass, evolving for 12 years, gradually increasing in volume with dysphagia and unilateral left ear ache, without dyspnea or dysphonia. There was no deterioration of the general status. Physical examination objectified an intraoral bulky mass, attached to the soft palate, emerging from the left palatine tonsil and anterior pilar areas, anteriorly and medially (Figure 1), there was no trismus with a normal appearance of the mucosa there.

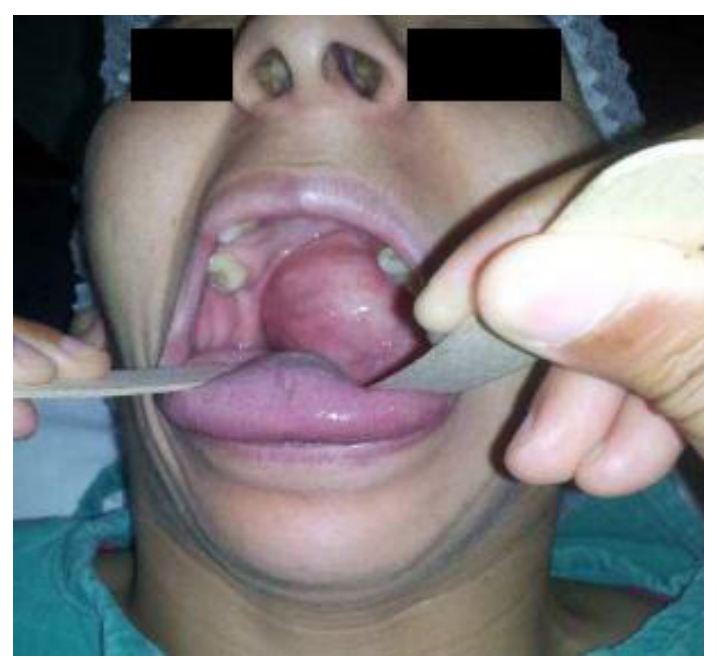

Figure 1: The intraoral bulky mass, attached to the soft palate, emerging from the left palatine tonsil and anterior pilar areas, anteriorly and medially 
Examination of the face found barely palpable tumefaction in left parotid area, which was hard, with no inflammatory signs or facial paralysis. The head and neck CT scan showed a very limited tissue process, of $7 \mathrm{~cm}$ of major axis, centered on the parapharyngeal lodge and the soft palate, narrowing the nasopharyngeal and oropharyngeal lights. Besides, it extends to the deep lobe of the left parotid gland and comes into contact with the external carotid artery, with loss of fat separation edging. This mass heightens heterogeneously after injection of product contrast. There was no bone lysis (Figure 2).

The patient had resection of the mass with a combined surgical approach, cervical parotid and endobuccal. Total parotidectomies with dissection of the facial nerve were performed (Figure 3). Histopathology of the specimen was in favor of a pleomorphic adenoma. The post-operative course was uneventful.

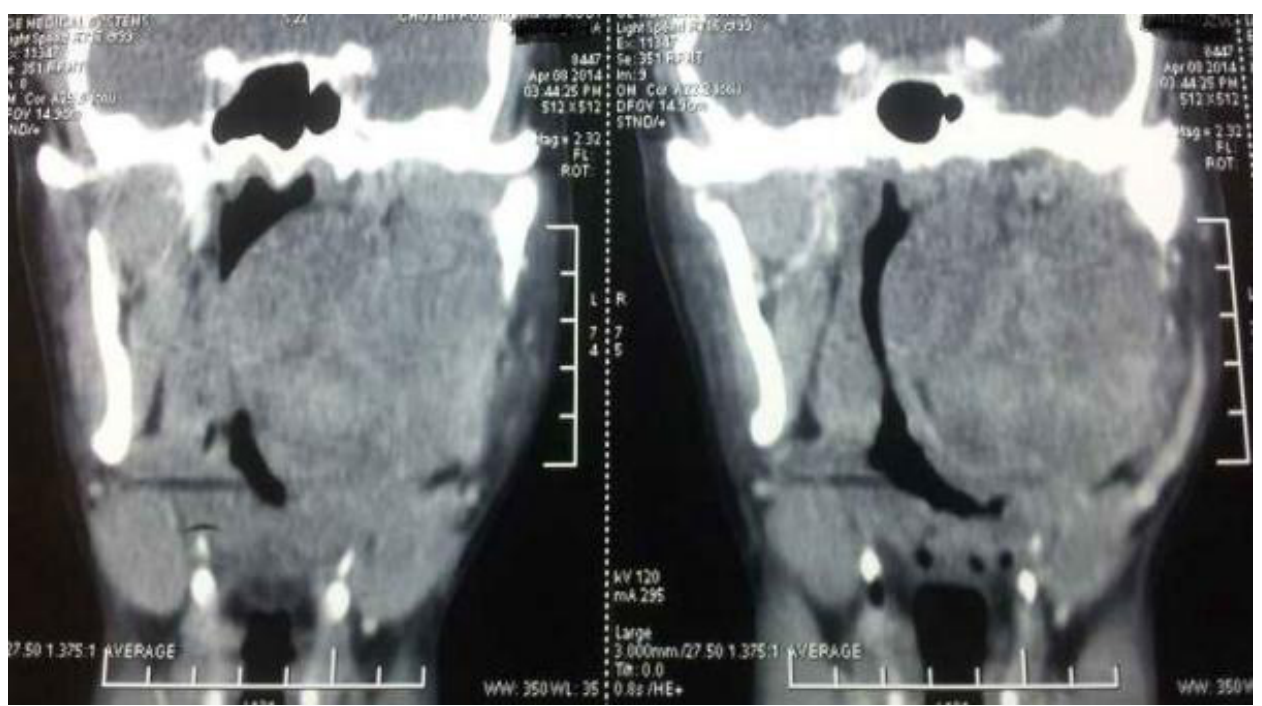

Figure 2: Cervical CT axial sections: important well limited mass occupying the left parapharyngeal space

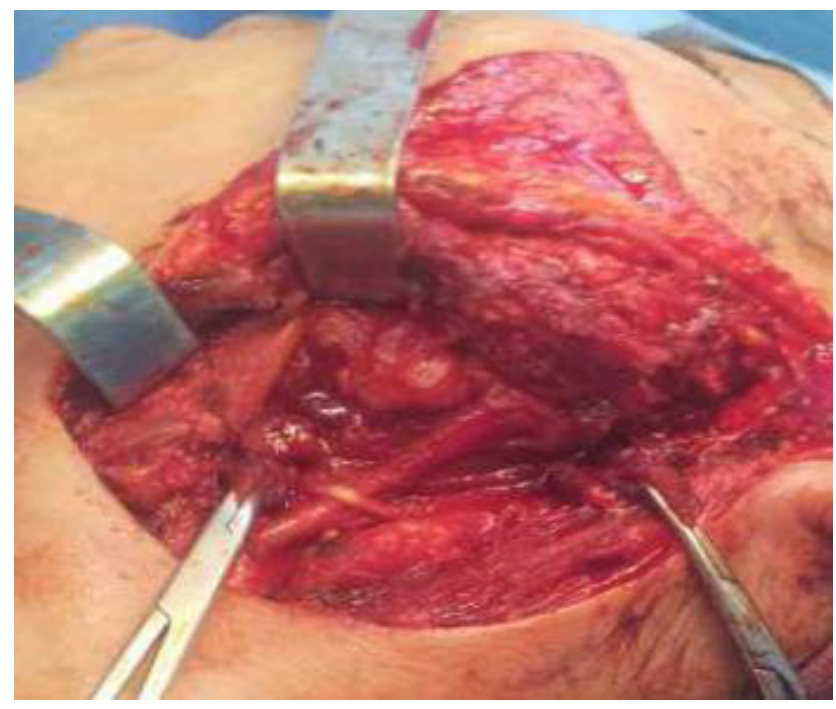

Figure 3: Surgical site after the removal of the mass and total parotidectomy: view in the left mandibular angle, Trans parotid approach

\section{Discussion}

Parapharyngeal space tumors are rare tumors, representing approximately 0.5 to $1 \%$ of all tumors of the head and neck [1]. The nature of the tumors developed in the retropharyngeal space is different from those encountered in the latero-pharyngeal space. Salivary primary tumors are the most frequent tumors in parapharyngeal spaces. They are original parotid, or developed from accessory salivary glands. They represent $40 \%$ to $50 \%$ of para-pharyngeal tumors and $90 \%$ are pleomorphic adenomas. The pleomorphic adenoma, developed from the "deep lobe" of the parotid [1,3], is the most frequent of tumors in the parapharyngeal space; yet only $1 \%$ of deep lobe tumors have a para-pharyngeal manifestation. Tumors of parapharyngeal spaces, by their development in a deep region limited by a bony frame, are in their initial phase, asymptomatic and diagnosis is often done when they reach a initial voluminous size, approximately $3 \mathrm{~cm}[1]$.

Tumors of the parapharyngeal space are found most often as a Intraoral mass or in the neck. Other signs are found, correlated with the mass effect, exerted by tumor on adjacent structures such as dysphagia, pharyngeal discomfort, rhinolalia and snoring. 
The sleep apnea syndrome has also been described. Physical examination is poor. He usually finds a non-pouring intraoral mass, covered by a smooth mucosa repressing the tonsil inside [4-6]. Tumors of the parapharyngeal space often constitute a diagnostic problem. CT and MRI are needed for the topographic diagnosis and to guide the etiological [7-9]. CT is the first line examination; It allows to differentiates, with a reliability from 75 to $90 \%$, between a tumor in reverse stylienne lodge a tumor of the pre-stylienne lodge [9].

It also allows studying the anatomical relationship of the tumor with the base of the skull, to study its vascularization, to properly evaluate the bony frame at the pterygoid processes, vertebral bodies; it detects the presence of calcifications [3]. The sensitivity of MRI in the topographical diagnosis of salivary tumors in the parapharyngeal space varies between 95\% and 100\% [6]. The typical feature of pleomorphic adenoma in MRI is a mass isointense T1, T2 hyperintense with festooned edge [8]. Intra-oral biopsies or by cervicotomy have to be avoided, because of the risk of opening a breach in the tumor capsule, increasing therefore the risk of recurrence. Parapharyngeal tumor's treatment is surgical. Several surgical approaches have been described.

The best surgical approach must allow good exposure to identify and protect neurovascular structures while ensuring complete removal of the tumor [9]. The elective approach is the cervical trans-parotid one. The trans-oral surgical approach is for independent small tumors of the parotid gland [8]. This technic has been described for the first time in 1950 by Ehrlich for extra parotid nonvascular tumors of small sizes. It is subject to lot of criticism; indeed the reduced workspace gives poor control of neurovascular structures and prevents from doing a complete excision of tumors. It can be combined with cervical approach, allowing control the deep part of the tumor. The transoral approach gives less postoperative complications according to Carrau et al. [9]. Postoperative recurrence rate of pleomorphic adenomas is $5 \%$ in the literature [9]. It may be due to a fragmentation of the tumor during its removal [5].

\section{Conclusion}

Tumors of the parapharyngeal space are rare. The diagnosis is often made at a late stage because of the slow evolution and deep anatomical situation. Their care requires a full radiological assessment (CT and MRI). Their treatment is surgical. The distinction between accessory salivary gland tumors and tumors of the deep parotid lobe is necessary to guide the selection of the surgical approach.

\section{References}

1. Makeieff M, Quaranta N, Guerrier B (2000) Tumeurs parapharyngées. Encycl Med Chir Oto-rhino-laryngologie 10: 14.

2. Günerí A, Günbay MU, Günerí EA, Ceryan K, Sütay S (1994) Management of parapharyngeal space cysts. J Laryngol Otol 108: 795-7.

3. Bozza F, Vigili MG, Ruscito P, Marzetti A, Marzetti F (2009) Surgical management of parapharyngeal space tumors: results of 10-year follow-up. Acta otorhinolaryngol ital 29: 10-5

4. Shahinian H, Dornier C, Fisch U (1995) Parapharyngeal space tumors: the infratemporal fossa approach. Skull Base Surg 5: 73-81.

5. Hakeem AH, Hazarika B, Pradhan SA, Kannan R (2009) Primary pleomorphic denoma of minor salivary gland in the parapharyngeal space. World J Surg Oncol 7: 85 .

6. Miller FR, Wanamaker JR, Lavertu P, Wood BG (1996) Magnetic resonance imaging and the management of parapharyngeal space tumors. Head Neck 18: 67-77. 7. Sergi B, Limongelli A, Scarano E, Fetoni AR, Paludetti G (2008) Giant deep lobe parotid gland 130 pleomorphic adenoma involving the parapharyngeal space. Report of three cases and review of the diagnostic and therapeutic approaches. Acta otorhinolaryngol Ital 28: 261-5.

8. Pang KP, Goh CHK, Tan HM (2002) Parapharyngeal space tumors: an 18 year review. J Laryngol otol 116: 170-5.

9. Bouilloud F, Jégoux F, Caze A, Godey B, Le Clech G (2008) Parapharyngeal tumors: Diagnosis and treatment [Tumeurs parapharyngées: diagnostic et traitement]. Ann Otolaryngol Chir Cervicofac 125: 181-7. 